\title{
Percepções Sobre a Criação de Reservas Orçamentárias em Processo Orçamentário Participativo
}

\section{Resumo}

Este trabalho, elaborado a partir de uma pesquisa empíricodescritiva, tem o objetivo de analisar o tema reserva orçamentária do ponto de vista da retórica, em uma abordagem de aproximação interpretativista por meio de um estudo de caso. Oferece uma visão alternativa aos trabalhos desenvolvidos sob a égide do positivismo, em que tudo o que se desenvolve nas organizações é estritamente racional. Além disso, desdobra o que se denominou, genericamente, reservas, como se fosse uma "caixa preta" em que tudo é igual e assim deve ser tratado. Foi escolhida uma organização de grande porte, com as complexidades, necessidades e tensões que ela proporciona. Existem três principais achados desta pesquisa. O primeiro é a ambiguidade de entendimento de reservas tanto como algo a ser evitado como também algo essencial à gestão, ou seja, quando existe, beneficia a organização. O segundo achado é que o entendimento negativo quanto à existência da reserva é acompanhado da negação da sua existência. $O$ terceiro achado é que o argumento para a não existência das reservas orçamentárias está baseado na estrutura que considera sistema de informações, metas derivadas das estratégias e intenso envolvimento da alta administração, o que inibiria a sua constituição. Como implicação, reflexão nas organizações ao tratar as reservas orçamentárias como algo a gerenciar e não simplesmente evitar.

Palavras-chave: Controle Gerencial; Orçamento; Reservas Orçamentárias; Análise de Discurso.

\section{Fábio Frezatti ${ }^{1}$}

Livre Docente pela Universidade de São Paulo (USP) e Professor Titular da Faculdade de Economia, Administração e Contabilidade (USP). Contato: Av.Prof. Luciano Gualberto, 908, FEA 3, Butantan, São Paulo, SP, CEP: 05508010.

E-mail: frezatti@usp.br

\section{Franciele Beck}

Mestre em Ciências Contábeis pela Universidade Regional de Blumenau (FURB). Contato: Rua Antonio da Veiga, 140, Victor Konder, Blumenau, SC, CEP: 89012-900.

E-mail: beck.franciele@gmail.com

\section{Júlio Orestes da Silva}

Mestre em Ciências Contábeis pela Universidade Regional de Blumenau (FURB) e Professor Assistente da Universidade Federal de Goiás. Contato: Caixa Postal 131, Campus II, FACE, Goiânia, G0, CEP: 74001-970.

E-mail: orestesj@gmail.com

10 primeiro autor agradece à FAPESP, ao CNPq e à CAPES pelo apoio proporcionado ao projeto de pesquisa que originou o trabalho. 


\section{Introdução}

A gestão empresarial demanda estrutura de planejamento e controle formalizado para possibilitar o desenvolvimento das operações, o acompanhamento do desempenho e, mesmo, a remuneração dos executivos. Nesse sentido, o planejamento estratégico, o orçamento empresarial e o Balanced Scorecard (BSC) se constituem em ferramentas para apoiar a gestão empresarial (Ferreira \& Otley, 2009; Merchant \& Van der Stede, 2007; Frezatti, Rocha, Nascimento, \& Junqueira, 2009). Em ambientes de maior estabilidade, o orçamento apresenta-se mais adequado do que em ambientes de alta volatilidade e risco (Chenhall \& Morris, 1986). Nenhuma literatura indica que o orçamento deixe de ser utilizado em ambientes mais voláteis, mas reconhece-se que a sua eficácia pode variar em função da evolução de inúmeras variáveis (Chenhall \& Morris, 1986; Miles \& Snow, 1978).

Nesse ponto a literatura pouco avança no sentido de questionar as adaptações que os profissionais desenvolvem para utilizar o orçamento. Afinal trata-se de um artefato que não é obrigatório nas organizações e cuja concepção e uso não são iguais. A teoria da Agência, conforme Jensen e Meckling (1976) e Lambert (2006), demanda instrumento de coordenação, objetivação de planejamento, mas o grau de formalização, abrangência e satisfação são legitimados pelo modelo de gestão de cada entidade. A teoria da agência apenas reconhece que instrumentos são demandados, mas não se atém a como devem ser estruturados ou disponibilizados.

Um dos elementos mais questionados quando se trata do orçamento formalizado nas organizações é a reserva orçamentária (budgetary slack), olhada dentro das mais variadas perspectivas. Nesse sentido, reserva orçamentária pode ser vista: como um valor que serve para cobrir incertezas (Thaten, Mahlendorf, \& Skiba, 2010); como uma questão ética (Hobson, Mellon, \& Stevens, 2011); como fruto da pressão do sistema orçamentário (Marginson \& Ogden, 2005); e como uma reação à política de remuneração da organização (Leavins, Omer, \& Vilutis, 1995). Por apresentar a combinação de diferentes paradigmas (Covaleski, Evans, Luft, \& Shields, 2003), parte das críticas à constituição de reservas orçamentárias decorre dos diferentes entendimentos. De uma maneira simplificada, a grande crítica à existência de reservas orçamentárias é a perda de referencial de desempenho que seja aceito como adequado no desempenho organizacional. Embora a reserva orçamentária possa ser definida de várias maneiras, em termos gerais, corresponde a valores de gastos maiores do que aqueles "adequados" e valores de receitas menores do que aqueles mais "adequados" ou esperados.

\section{Problematização e Questão de Pesquisa}

Algumas alternativas de tratamento para as reservas são possíveis e uma delas consiste em tratar o tema com maior flexibilidade. Isso é possível mediante revisões do orçamento (Hansen \& Van der Stede, 2004). Como consequência, resultados são alterados, metas podem ser ajustadas eventualmente e as expectativas que o sócio tinha podem ser muito alteradas. Ao fazer isso, o instrumento perde a sua estabilidade no relacionamento entre executivos e sócios no que se refere aos compromissos, o que representa um problema para o processo de agência. O sócio espera dos executivos o cumprimento de suas metas, ainda que o ambiente (interno e externo) seja volátil ou mesmo agressivo. Espera que o agente dedique o melhor de si nas atividades que lhe foram confiadas e gere os resultados prometidos.

Como lidar com isso se a flexibilidade não está presente? Do lado dos executivos, as questões comportamentais se acentuam: i) Como serei avaliado? ii) Se o ambiente externo se modificar, como vou obter recursos para atuar? iii) Terei mais capacidade de recuperação do que os meus pares? iv) Como o meu desempenho vai influenciar a minha carreira e a minha avaliação?

O estudo desenvolvido por Yuen (2004) demonstrou que essas tensões levam os executivos a criar reservas orçamentárias para a sua proteção. São folgas que não permitem à organização estabelecer patamares de desempenho efetivamente desafiadores e, ao mesmo tempo, proporcionam proteção para que o executivo possa manter suas metas com mais gastos ou menos receitas. Podem ser feitas com ou sem o consentimento de níveis superiores e, no pior dos casos, existem sem que se saiba. 
A literatura tem tratado o orçamento de várias maneiras, mas, em geral, as pesquisas são muito críticas em relação ao processo e questionam elementos que o compõem. Dentre esses elementos, a reserva orçamentária é uma das mais questionadas (Hartmann \& Maas, 2010; Davila \& Wouters, 2005; Hewege, 2012; Merchant \& Van der Stede, 2007). A maior parte dos trabalhos se preocupa em mostrar a folga e seus efeitos indesejáveis sobre a gestão. Contudo, a indicação de soluções para problemas gerados pelas reservas ainda é mais escassa (Frezatti, Relvas, Junqueira, Nascimento, \& Oyadomari, 2010).

Como se percebe, embora a definição de reserva possa ser algo relativamente simples, a sua materialização e o consequente tratamento podem ocorrer levando em conta diferentes perspectivas ou vertentes epistemológicas. Essas vertentes dependem de como os pesquisadores entendem o mundo em termos de realidade, o que torna o tema muito propício a críticas e menos em termos de propostas de soluções. Como decorrência, apresenta-se uma dificuldade adicional, pois a literatura é muito fragmentada e nem sempre alinhada epistemologicamente.

Essa é uma oportunidade relevante, pois a discussão sobre estabelecimento e existência de reserva carece de um construto teórico abrangente para analisar e permitir o entendimento do fenômeno. Dessa maneira, a questão de pesquisa que norteia o trabalho é a seguinte: Devemos evitar ou entender e gerenciar a constituição de reservas orçamentárias?

Este trabalho se propõe a contribuir de duas maneiras, sendo: investigar os diferentes tipos de entendimento de reservas orçamentárias ou possíveis de serem geradas, bem como avançar no entendimento dos seus antecedentes. Para que isso seja possível, a pesquisa será desenvolvida de maneira alternativa à abordagem predominantemente proposta nos artigos publicados, à abordagem positivista, que entende que a reserva orçamentária é um problema e, a partir daí, take for grant, ou seja, como evitar o problema sem questionamento, se é, ou não, um problema. Para capturar elementos que possam ser considerados alternativos, será utilizada a abordagem interpretativista.

\section{Revisão da Literatura}

A revisão da literatura pode ser dividida em quatro elementos: (i) controle gerencial, (ii) orçamento, (iii) reservas orçamentárias e (iv) construto das reservas orçamentárias.

\subsection{Controle gerencial}

A partir da definição de Anthony (1970), o processo de controle gerencial valorizou a contabilidade gerencial, pois ela passou a ser vista como parte de "um conjunto de atividades desenvolvidas para assegurar que os planos gerenciais sejam atingidos" (Anthony \& Govindarajan, 2008). Nessa perspectiva, as estratégias da empresa são valorizadas e uma dada estrutura, conjunto de artefatos, rotinas e procedimentos são desenvolvidos em uma organização. O conjunto de artefatos pode ser variado e busca atender a funções relevantes do modelo de gestão da organização, mas os mais citados são o planejamento estratégico, BSC, orçamento e controle orçamentário (Frezatti et al., 2009). Existe uma hierarquia e sequência de desenvolvimento desses artefatos nas organizações e a sua estruturação está ligada à maneira como os gestores desenvolvem suas atividades.

É esperado que o relacionamento entre os artefatos, hierarquia e sequência proporcionem algum nível de alinhamento que permita a gestão da organização de maneira eficiente e eficaz. Esse conjunto de artefatos, conforme Malmi e Brown (2008), pode ser visto como pacotes e relacionam os vários sistemas de controle (cibernéticos, administrativos e socioideológicos) da organização, de maneira que a remuneração e reconhecimento decorram desses elementos. Tal relacionamento, que pode variar em termos de existência dos artefatos, amplitude e maneira de serem utilizados, ao mesmo tempo, provoca e equilibra as várias tensões das organizações no sentido da execução das atividades. 


\subsection{Orçamento}

Reconhecido a partir de seus conjuntos - como o plano financeiro das organizações -, o orçamento decorre do planejamento estratégico, relaciona-se com o BSC quando existir na organização e é acompanhado pelo controle orçamentário (Frezatti, 2007). Pode ser usado para vários propósitos e de maneira combinada, tais como planejamento, coordenação e organização de atividades, alocação de recursos, motivação de funcionários e expressa a conformidade com as normas sociais (Covaleski et al., 2003). Por sua vez, podemos encontrar as seguintes razões para dispor do orçamento nas organizações. Hansen e van der Stede (2004) mencionam: plano operacional, elemento para avaliação de desempenho, instrumento para comunicação de objetivos e formação de estratégias. Em outras palavras, é um instrumento com muitas nuances e potenciais conflitos, no tempo, na hierarquia e mesmo no direcionamento. Afinal, se, ao mesmo tempo, o instrumento aponta para o futuro contemplando as estratégias, demanda definição de metas que serão utilizadas para avaliar desempenho de áreas e pessoas. Como consequência, o potencial conflito está instalado na origem. As tensões e interesses precisam ser tratados e gerenciados para que o instrumento seja utilizado dentro dos conflitos internos das organizações. Ora, nada mais natural às pessoas quando operacionalizam uma estratégia em uma meta, na dúvida em face das incertezas, optar por uma meta que não as desfavoreça.

A participação na elaboração e na cobrança de resultados do orçamento é o ponto inicial, dado que, se não existe participação, se ele é desenvolvido de maneira top-down, a discussão sobre reservas não faz sentido. De qualquer forma, participação não é um tema que possa ser desenvolvido de maneira binária, ou seja, existe ou não existe (Kenis, 1979), trazendo efeito sobre o processo de planejamento. Levando-se em conta a perspectiva de participação, em algum grau, vários conflitos passam a existir no momento de estabelecimento de metas que, uma vez aprovadas, devem ser perseguidas, atingidas e recompensadas (Covaleski et al., 2003). A ferramenta propriamente dita proporciona expectativa de controle, por alguns denominada ilusão do controle, pelo fato de que o artefato em si não o proporciona, mas gera essa percepção (Rosanas \& Velilla, 2005).

A expectativa de atuação racional, alinhada com a teoria da agência, em ambiente participativo de planejamento é que as metas contenham desafios e sejam exequíveis (Welsch, 1986). Essa maneira de olhar o relacionamento entre pessoas e coisas é muito relevante para a perspectiva organizacional e suas relações causais. Já que a construção do orçamento é conjunta e uma das perspectivas é dispor de um artefato que persiga o aumento da eficiência, ter reservas em um orçamento pode significar a perda da informação que representa a otimização de resultados. Por outro lado, identificar o que é uma reserva não é uma tarefa fácil quando se vive um ambiente de mudança e incerteza.

\subsection{Reservas orçamentárias}

A forma com que a empresa se estrutura, planeja, aloca e utiliza seus recursos para a consecução de seus objetivos é tratada na literatura em Contabilidade Gerencial sob diversos enfoques e perspectivas, sendo predominante a abordagem positivista, entre as quais se aponta a pesquisa relacionada às reservas de recursos, discutida nos estudos de Mohamed (1973), Bourgeois (1981), Merchant (1985), Cheng e Kesner (1997), Tan e Peng (2003) e Chen e Huang (2010).

Partindo do modelo econômico, Mohamed (1973, p. 535) define reserva de recursos como "a diferença entre o total de recursos disponíveis para uma empresa e o total necessário para manter a coalizão da organização". Nesse aspecto, Merchant (1985) destaca como uma modalidade importante de reserva a reserva orçamentária. A compreensão acerca da definição dessa modalidade de reserva perpassa o fato de que seu surgimento está diretamente relacionado ao processo organizacional de alocação de recursos, em específico, suas imperfeições (Mohamed, 1973). 
Segundo Covaleski, Evans, Luft e Shields (2003), a alocação de recursos está entre uma das muitas finalidades do orçamento, juntamente com o planejamento e coordenação das atividades desenvolvidas pela organização, a motivação de empregados, o estabelecimento de normas sociais. Dessa forma, o processo orçamentário, seus aspectos, particularidades e configurações representam um campo amplo de investigação desse fenômeno, compreendendo desde a caracterização, e motivos para a criação de reservas orçamentárias, às aplicações e relações específicas dessa prática, denotando interesse e preocupação por parte da academia e organizações (Merchant, 1985; Yuen, 2004; Davila \& Wouters, 2005).

Partindo desse retrospecto, apresentam-se na Figura 1 as definições de reservas orçamentárias levantadas nas pesquisas, tendo como objetivo a conceituação e posterior delineamento das perspectivas teóricas e empíricas verificadas na revisão da literatura.

\begin{tabular}{|ll|}
\hline \multicolumn{1}{|c|}{ Definição } & \multicolumn{1}{c|}{ Autor (es) } \\
\hline $\begin{array}{l}\text { "Reserva orçamentária é definida como o montante pelo qual um subordinado } \\
\text { subestima sua capacidade produtiva, quando dada a oportunidade de selecionar } \\
\text { um padrão contra o qual seu desempenho será avaliado." }\end{array}$ & Young (1985, p. 831, grifo nosso) \\
\hline $\begin{array}{l}\text { "Reserva orçamentária pode ser definida como o excesso de montante orçado } \\
\text { em uma área sobre o que é necessário." }\end{array}$ & $\begin{array}{l}\text { Merchant (1985, p. 201, grifos } \\
\text { nossos) }\end{array}$ \\
\hline $\begin{array}{l}\text { "Viés orçamentário é definido como a diferença deliberadamente criada } \\
\text { entre a previsão orçamentária 'estimativa de orçamento honesto' e o valor do } \\
\text { orçamento 'proposta de orçamento'." }\end{array}$ & Lukka (1988, p. 282, grifos nossos) \\
\hline $\begin{array}{l}\text { "Reserva pode ser definida como a subestimação intencional de receitas } \\
\text { e capacidades produtivas e/ou superestimação de custos e recursos } \\
\text { necessários para completar uma tarefa orçamentária." }\end{array}$ & $\begin{array}{l}\text { Dunk e Nouri (1998, p. 73, grifos } \\
\text { nossos) }\end{array}$ \\
\hline $\begin{array}{l}\text { "Reservas envolvem o consumo de recursos da organização em excesso ao } \\
\text { que são demandados e os funcionários não podem facilmente explicar a } \\
\text { contribuição desses gastos para os objetivos organizacionais." }\end{array}$ & $\begin{array}{l}\text { Merchant e van der Stede (2007, } \\
\text { p.185, grifos nossos) }\end{array}$ \\
\hline $\begin{array}{l}\text { "Reserva orçamentária é criada quando um subordinado subestima suas } \\
\text { capacidades ou os recursos de seu orçamento em uma unidade de negócios." }\end{array}$ & $\begin{array}{l}\text { Hobson, Mellon e Stevens (2011, p. } \\
\text { 88, grifo nosso) }\end{array}$ \\
\hline $\begin{array}{l}\text { "Definida como a diferença entre os recursos orçados e os recursos necessários } \\
\text { para atingir os objetivos da organização de forma eficiente." }\end{array}$ & $\begin{array}{l}\text { Kilfoyle e Richardson (2011, p. 186, } \\
\text { grifo nosso) }\end{array}$ \\
\hline
\end{tabular}

Figura 1. Definições de Reserva Orçamentária

Fonte: Desenvolvido com base na literatura investigada.

O que chama a atenção em todas as referências é que o gestor tem consciência e racionalmente consegue perceber que tem um valor sub ou superestimado considerado no processo orçamentário. Isso pode ser constatado pelo uso das palavras: "subestimar", "excesso em relação ao necessário", "deliberadamente criada", "intencionalmente criada", etc. A lógica da racionalidade considerada leva em conta que o gestor faz a reserva conscientemente e poderia não fazê-lo. Essa é uma discussão relevante: ele teria a chance de não fazê-lo? Sem uma abordagem que permita conviver com os gestores, qualquer avanço nessa discussão torna-se limitado. Essa é a motivação de buscar uma alternativa paradigmática que proporcione olhar diferente daquele oferecido pela perspectiva racional positivista.

\subsection{Construto das reservas orçamentárias}

As definições de reserva orçamentária citadas no item anterior reforçam o desenvolvimento da temática na literatura contábil e sua intrínseca associação às motivações quanto à criação dessas reservas, revelando-se, portanto, o ponto-chave da discussão. Como se pode perceber, quatro dimensões devem ser consideradas ao tratar as reservas e são suportadas pela literatura: 
- A existência da reserva: subestimar receitas e superestimar gastos;

- Intencionalidade da ação: foi gerada deliberadamente, independentemente de gerar benefícios;

- Razões para a reserva ser criada; $\mathrm{e}$

- Benefício da ação: pode existir ou pode não existir.

O primeiro elemento, a existência de reservas, pode ser discutido a priori, embora subestimar ou superestimar uma dada meta tenha que ser orientado para alguma referência (Young, 1985; Lukka, 1988; Dunk \& Nouri, 1998; Hobson et al., 2011). Qual é e onde estaria essa referência? No passado, presente, futuro? Estariam disponíveis internamente ou externamente? Se for o passado, despreza toda a perspectiva da própria definição de planejamento que se caracteriza por ser "decisão antecipada" (Welsch, 1986). Se o futuro simplesmente repetir o passado, o que não é o mais característico, pode ser uma alternativa plausível; caso contrário, não deve ser essa a perspectiva de comparação. De qualquer forma, é inegável o poder da referência passada, histórica, pelo fato de ser entendida como "objetiva", ou seja, algo que já ocorreu. A constituição de reservas, faz ou fez parte da realidade vivenciada pela organização e assim é reconhecida. Ressalta-se que ouvir o gestor para entender se ele acredita que existam reservas é relevante, pois é o primeiro passo para analisar se a criação é intencional, o porquê da reserva ser constituída e ainda, quais os impactos gerados.

O segundo elemento, decorrente do primeiro, é de difícil tratamento, pois é extremamente subjetivo (Young, 1985; Lukka, 1988; Dunk \& Nouri, 1998). Como saber se os gestores, intencionalmente, subestimaram ou superestimaram metas? Em decorrência disso, aceita-se o pressuposto de que, ao existir benefício, a reserva foi consequentemente intencional. $\mathrm{O}$ fato de existir sistema de remuneração que premia os executivos que atingirem dadas metas faz com que o intencional seja visto como latente, como possível. A aceitação da intenção pressupõe que existam condições: claro entendimento da construção das metas, disponibilidade de informações, sistemas de informações, claro conhecimento conceitual e prático, além de estrutura de planejamento adequada quanto a cronograma, treinamento e estrutura organizacional (Frezatti, Nascimento, Junqueira, \& Relvas, 2011). Caso essas condições não sejam encontradas, pode-se dizer que não foi intencional, mas, sim, por desconhecimento, ausência de tempo mínimo para obter informações melhores, etc.

De qualquer forma, alguns autores citados não se preocupam com a ausência de condições, dado o seu posicionamento ontológico: o fato de existir subestimação ou superestimação não deveria ocorrer, independentemente de possíveis causas. Seria algo semelhante a dizer que o que se planeja "tem que ocorrer", como se o ambiente vivido fosse perfeitamente previsível, a comunicação mais do que adequada e o grau de conhecimento dos gestores no mais alto nível possível. Não é de se estranhar que essa vertente não consiga avançar no conhecimento sobre estabelecimento de reservas, já que não se preocupa com causas fora da mais pura racionalidade. Os estudos de Covaleski et al. (2003) vêm contribuir para um melhor entendimento das tensões existentes nesse ambiente, combinando a racionalidade (perspectiva econômica), questões motivacionais (abordagem psicológica) e o poder (abordagem sociológica). Esse conjunto permite entender que as diferentes abordagens trazem influências mútuas dentro da organização.

O terceiro elemento, as razões para se desenvolver uma reserva, pode trazer várias respostas possíveis, tais como: (i) a pressão decorrente da gestão de topo para atingir o crescimento de lucro anual do orçamento (Mohamed, 1973); (ii) como um hedge contra a incerteza (Mohamed, 1973; Merchant, 1985; Nouri, 1994; Leavins, Omer, \& Vilutis, 1995; Davis, Dezoort, \& Kopp, 2006); (iii) estrutura organizacional e controle orçamentário, participação no orçamento e assimetria informacional entre os envolvidos, tratados, por exemplo, nos estudos de Bruns e Waterhouse (1975), Kenis (1979), Merchant (1985), Young (1985), Brownell e McInnes (1986), Lukka (1988), Chow, Cooper e Waller (1988), Dunk (1993), Leavins, Omer e Vilutis (1995), Yuen (2004); (iv) a assimetria informacional, por outro lado, é tida como uma variável que influencia diretamente na criação e proporção dessas reservas (Dunk, 1993; Yuen, 2004), (v) o nível de descentralização de uma organização (Leavins et al., 1995); e (vi) comunicação inadequada (Yuen, 2004, p. 520). Indica-se um leque variado de motivações para o desenvolvimento de reserva, profundamente relacionado às configurações e arranjos organizacionais. 
O quarto elemento, o benefício da reserva, está intrinsecamente relacionado à remuneração dos gerentes (Mohamed, 1973; Leavins et al., 1995). Embora não seja o único tipo de benefício. Dessa forma, a literatura confere indícios de que, quando o desempenho do orçamento está ligado ao sistema de recompensa da organização, os gerentes (agentes) são motivados a criar reservas em resposta à expectativa de recompensa pelo alcance de suas metas, ou seja, ao intuito de melhorar sua perspectiva de remuneração (Brownel \& Mcinnes, 1986; Dunk, 1993; Leavins, Omer, \& Vilutis, 1995; Yuen, 2004; Church, Hannan, \& Kuang, 2012). Ressalta a opinião do gestor para os possíveis benefícios, ou não, da reserva orçamentária.

\section{Metodologia}

A retórica é a base da estrutura metodológica desta pesquisa, e o entendimento dos discursos organizacionais a partir de sua configuração argumentativa é a forma usada para captar as informações necessárias à análise (Giddens, 1979; Fairclough, 1992; Torfing, 1999; Dittrich, 2008; Kakkuriknuuttila, Lukka \& Kuorikoski, 2008; Carrieri et al., 2009; Moizer, 2009).

Utiliza-se como pano de fundo à estruturação da análise a retórica dos discursos organizacionais sob o enfoque dos argumentos de ordem técnica, emotiva e representacional (Dittrich, 2008). Na Figura 2, delimitam-se as dimensões pretendidas, suas respectivas descrições com base na literatura investigada, assim como o exemplo de sua caracterização na análise.

\begin{tabular}{|c|c|c|}
\hline Dimensão & Descrição & Caracterização na análise \\
\hline $\begin{array}{l}\text { Técnica } \\
\text { (racionalizadora) }\end{array}$ & $\begin{array}{l}\text { Ordem do conhecer e do entender. } \\
\text { Preceitos de ordem técnica que levam ao } \\
\text { entendimento da opinião e justificativas sobre os } \\
\text { quais o discurso se sustenta. } \\
\text { Responde à questão: "Por que a opinião é } \\
\text { verossímil?" }\end{array}$ & $\begin{array}{l}\text { Sujeito 1:"Analisamos quantos por cento } \\
\text { está sendo o custo direto em relação à } \\
\text { receita líquida, por exemplo, e até o conselho } \\
\text { de administração, diretoria e gerência } \\
\text { acompanham." }\end{array}$ \\
\hline Emotiva & $\begin{array}{l}\text { Ordem do sensibilizar e do atrair; } \\
\text { Evidencia as razões que tornam os argumentos } \\
\text { bons, por que vale a pena assumi-los afinal, e o } \\
\text { que se pode obter de benefício, adotando-o; } \\
\text { Responde a questão: por que merece ser adotada? } \\
\text { Ordem do sensibilizar e do atrair. } \\
\text { Evidencia as razões que tornam os argumentos } \\
\text { bons, por que vale a pena assumi-los, afinal o que } \\
\text { se pode obter de benefício, adotando-o? } \\
\text { Responde à questão: "Por que merece ser } \\
\text { adotada?". }\end{array}$ & $\begin{array}{l}\text { Sujeito 3: "A prática é tolerável em algumas } \\
\text { circunstâncias e é recomendável para não } \\
\text { correr riscos. Pode ter um custo adicional para } \\
\text { trabalhar sábado ou domingo para atingir } \\
\text { uma meta. É uma margem de segurança para } \\
\text { aproveitar a venda dos Dias dos Pais, por } \\
\text { exemplo, que é uma meta maior." }\end{array}$ \\
\hline Representacional & $\begin{array}{l}\text { Ordem do crer e do legitimar. } \\
\text { Trata do ethos prévio - institucional ou pessoal - } \\
\text { ou seja, a constituição de um discurso capaz de } \\
\text { conquistar a confiança do interlocutor. } \\
\text { Responde à questão: "Por que merece confiança?" }\end{array}$ & $\begin{array}{l}\text { Sujeito 3: "Intenção de fazer a reserva é uma } \\
\text { questão de arte, dependendo do nível do } \\
\text { funcionário, inadmissivel". }\end{array}$ \\
\hline
\end{tabular}

Figura 2. Aplicação da retórica como metodologia investigativa

Fonte: Desenvolvido com base em Dittrich (2008)

Conforme Dittrich (2008, p. 35) em uma argumentação “a técnica está para a racionalização assim como a emotividade para a sensibilidade e a representação para a confiabilidade". Nesse sentido, busca-se por meio dessas três dimensões, analisar as nuances dos discursos relacionados às reservas orçamentárias na empresa analisada.

A estruturação metodológica leva em conta as diretrizes gerais de estudo de caso propostas por Yin (2005), abordagem direcional em termos do tipo de contribuição, tratada por Keating (1995), e estruturação usando a retórica e aproximação interpretativista discutida por Alvesson (2003). 
As questões metodológicas demandadas em termos de especificação para a pesquisa são: (i) estudo de caso, (ii) coleta de dados e (iii) estrutura das entrevistas.

\subsection{Estudo de caso}

Pelo fato de se tratar de tema complexo que pode ser tratado a partir de vários paradigmas, envolvendo pessoas em vários níveis, o método do caso se mostra adequado (Yin, 2005; Kakkuriknuuttila et al., 2008).

Por sua vez, a empresa a ser pesquisada deve ter (i) porte, (ii) complexidade de operações, (iii) algum nível de participação dos executivos no modelo de planejamento e controle não exclusivo do topo da pirâmide, (iv) existência de artefatos de planejamento e controle cumprindo funções de coordenação, definição dos objetivos da empresa, plano operacional e referencial para acompanhamento do desempenho e feedback.

\subsubsection{Descrição da empresa}

A empresa selecionada possui 55 anos de história e atua no segmento têxtil. Para maior caracterização, ressalta-se que ela apresenta um quadro de aproximadamente 2.300 funcionários, distribuídos em seis unidades, nos estados de Santa Catarina, Paraná e São Paulo. Sob o aspecto de estrutura de propriedade e controle, a empresa corresponde a uma sociedade anônima de capital fechado, cujo controle pertence à família fundadora do negócio, que atualmente possui a gestão familiar concentrada em sua segunda geração.

A seleção dessa empresa para investigação do fenômeno de criação de reservas orçamentárias pontua-se na maturidade da empresa e nos seus controles gerenciais, em específico pela utilização do orçamento. Destaca-se também a disponibilidade de acesso à organização, fator de extrema importância em um estudo de profundidade.

\subsubsection{Estrutura organizacional e localização dos respondentes}

O organograma da empresa é apresentado na Figura 3, demonstrando a hierarquia em relação aos participantes do estudo.

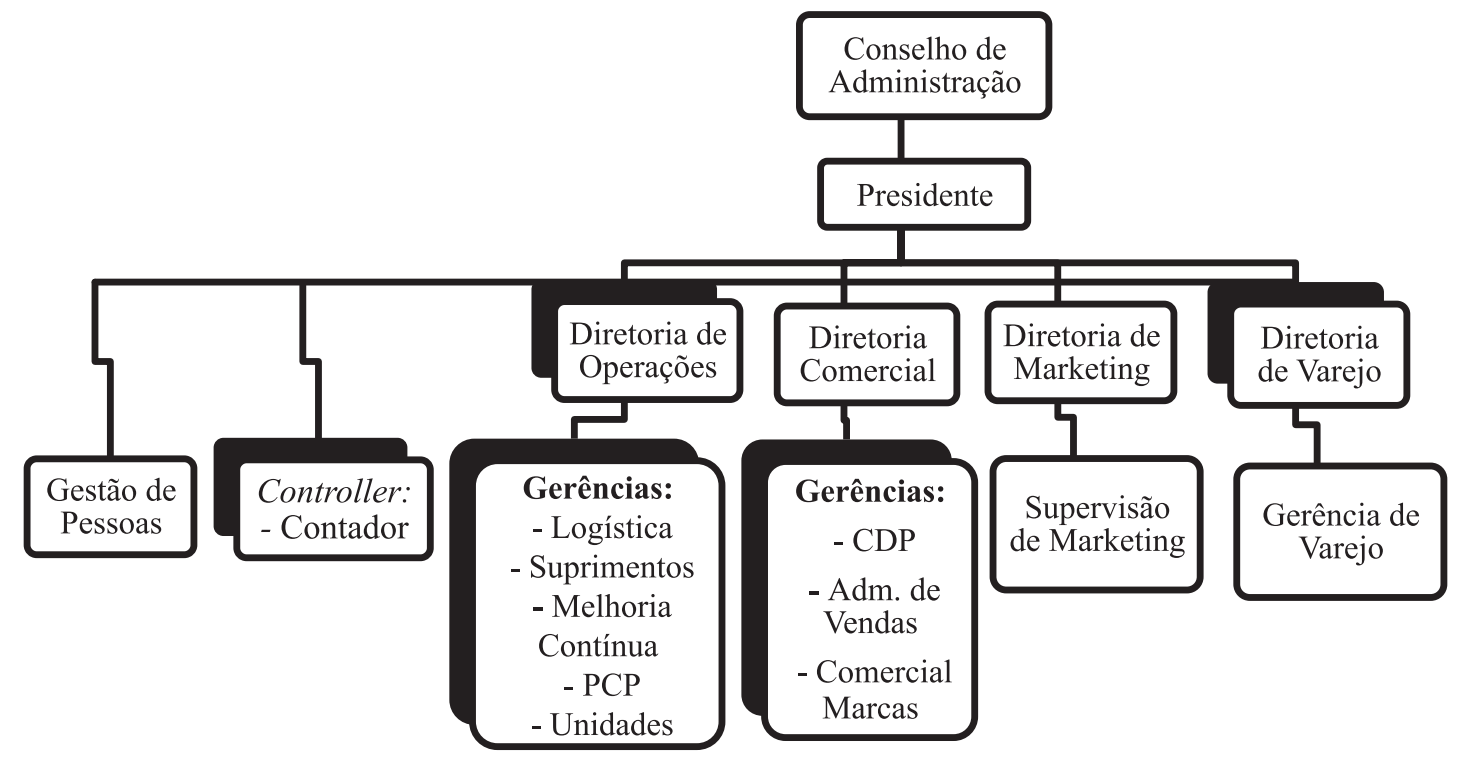

Figura 3. Organograma Formal da Empresa em 31/12/2011

Fonte: Adaptado do Relatório de Sustentabilidade 2011 da empresa. 
Os respondentes demandados são os executivos envolvidos no processo de planejamento e que podem influenciar e ser influenciados pelas reservas. $O$ fato de existirem respondentes de níveis diferentes e áreas funcionais diferentes permite entender elementos relevantes da organização dentro da abordagem de saturação, que valida os discursos percebidos. Dentro do organograma da empresa são: Conselho de Administração, presidente, diretores, gerentes que respondem para os diretores, e supervisões de área. Pela perspectiva da empresa, foram entrevistados os seguintes executivos:

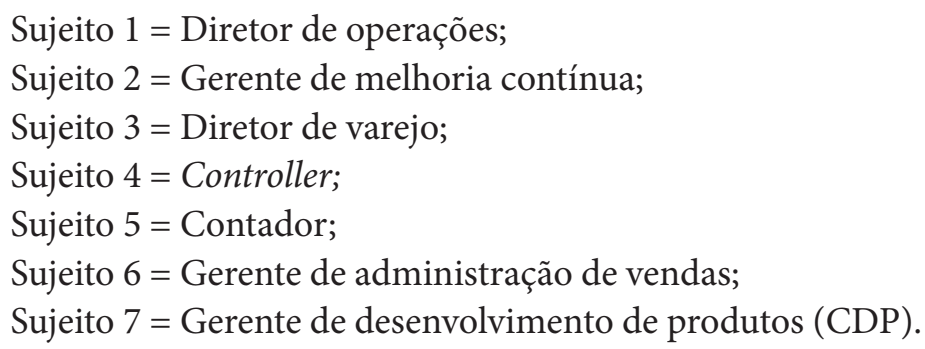

Os respondentes foram escolhidos (diretores e gerentes) por estarem ligados aos artefatos planejamento estratégico e orçamento. No caso específico dos gerentes, trata-se do nível que elabora o orçamento e discute com o diretor. Os níveis inferiores a eles não participam do processo. Por outro lado, foram escolhidos executivos de diferentes áreas para verificar as diferentes percepções e comportamentos relacionados ao orçamento, em específico no que se refere às reservas orçamentárias.

\subsection{Coleta de dados}

Foram planejados vários mecanismos de coleta de dados. Destaca-se a busca de informações por meio de documentos, mídias e no sítio eletrônico da empresa. Assim como foram realizadas entrevistas preliminares, seguida de entrevistas específicas no que se refere às reservas orçamentárias.

\subsubsection{Dados obtidos por meio de arquivos e site}

Dizem respeito às informações gerais sobre a empresa, que têm acesso público e servem para os pesquisadores entenderem a organização antes de um acesso mais profundo. Cita-se a utilização dos relatórios de sustentabilidade de 2011, 2010 e 2009, disponibilizados pela empresa, assim como as mídias e informações identificadas em seu sítio eletrônico.

\subsubsection{Entrevistas preliminares}

A interação ocorreu por meio de entrevistas não estruturadas desenvolvidas com quatro executivos, sendo diretor de operações, controller, contador e analista financeiro. Essas entrevistas tiveram o objetivo de entender a espinha dorsal do orçamento. Foram obtidas informações que proporcionaram entendimento sobre o modelo de gestão da organização, forma de trabalho e papel do orçamento na organização. Pode-se dizer, a partir das entrevistas, que:

- o modelo de gestão tem participação de, pelo menos, dois níveis abaixo da presidência (Leavins, Omer, \& Vilutis, 1995);

- os artefatos de planejamento e controle existem na organização: planejamento estratégico, orçamento, BSC, controle orçamentário, sistema de remuneração variável (Hansen \& Van der Stede, 2004); 
- as funções demandadas pelo modelo de gestão foram identificadas e são atendidas pelos artefatos, conforme Figura 3 (Hansen \& Van der Stede, 2004);

A empresa vive um momento de crescimento em que as metas têm sido batidas pelos funcionários. A maneira como o planejamento e controle são aplicados na empresa é destacada na Figura 4:

\begin{tabular}{|c|c|c|c|c|}
\hline Descrição & Coordenação & $\begin{array}{l}\text { Plano operacional } \\
\text { (com os objetivos } \\
\text { da empresa) }\end{array}$ & $\begin{array}{c}\text { Referencial para } \\
\text { acompanhamento e } \\
\text { feedback }\end{array}$ & $\begin{array}{l}\text { Instrumento para } \\
\text { implementação de } \\
\text { estratégias }\end{array}$ \\
\hline $\begin{array}{l}\text { Planejamento } \\
\text { estratégico }\end{array}$ & $\begin{array}{l}\text { Principalmente } \\
\text { comercial para o longo } \\
\text { prazo }\end{array}$ & - & - & - \\
\hline Orçamento & - & $\begin{array}{l}\text { Traz a visão única } \\
\text { para a empresa toda }\end{array}$ & $\begin{array}{l}\text { Leva em conta as } \\
\text { metas definidas no } \\
\text { planejamento estratégico }\end{array}$ & $\begin{array}{l}\text { Implementa as decisões } \\
\text { do planejamento } \\
\text { estratégico }\end{array}$ \\
\hline $\begin{array}{l}\text { Orçamento de } \\
\text { investimento }\end{array}$ & $\begin{array}{l}\text { Deriva das análises } \\
\text { do planejamento } \\
\text { estratégico }\end{array}$ & - & $\begin{array}{l}\text { Acompanhado } \\
\text { mensalmente }\end{array}$ & - \\
\hline BSC & $\begin{array}{l}\text { Existe, mas de forma } \\
\text { parcial }\end{array}$ & $\begin{array}{l}\text { Existe, mas de } \\
\text { forma parcial }\end{array}$ & $\begin{array}{l}\text { Existe, mas de forma } \\
\text { parcial }\end{array}$ & $\begin{array}{l}\text { Existe, mas de forma } \\
\text { parcial }\end{array}$ \\
\hline $\begin{array}{l}\text { Controle } \\
\text { orçamentário }\end{array}$ & - & - & Ocorre mensalmente & - \\
\hline
\end{tabular}

Figura 4. Especificação das Funções Demandadas pelo Modelo de Gestão

Fonte: Desenvolvido com base em Hansen e Van der Stede (2004).

As entrevistas confirmaram a existência do planejamento estratégico, do orçamento, e do controle orçamentário mensal. Os jargões internos são bem aderentes e são exemplificados: contrato de resultados, grupo gestor, etc. O horizonte de longo prazo de três anos é alinhado com o instrumento de planejamento de longo prazo de cinco anos. Ficou claro que o planejamento estratégico envolve a diretoria e a gerência a ela subordinada, e o orçamento decorre da sua montagem. A palavra integração entre os elementos foi muito enfatizada.

Existe certa autonomia no nível de diretoria para definição de seus gastos orçamentários, sendo focados primordialmente: (i) pessoas, (ii) gastos gerais e (iii) investimentos da área. A ótica de análise de gastos leva em conta (i) as ocorrências passadas, (ii) a necessidade de gastos em decorrência do momento presente (base zero) e a (iii) demanda futura em função do crescimento. Existe vínculo do orçamento com o plano de remuneração da empresa, levando em conta as metas do planejamento estratégico aplicadas à empresa como um todo, não sendo controlado o seu cumprimento nos departamentos da empresa por meio do acompanhamento orçamentário. Não percebem o orçamento como um instrumento engessado, pois o crescimento tem sido maior do que o que tem sido planejado, por isso, o orçamento é entendido como balizador, já que precisa ser adaptado em função do crescimento da organização. O orçamento é montado por centros de custos com suas várias contas, por meio de sistema de contabilidade que cruza com sistema integrado.

O foco de análise do orçamento é a margem de contribuição por marca, contendo os grupos de produtos e grupos de representantes e clientes. A existência de mecanismos participativos e de reflexão (orçamento base-zero para alguns elementos) proporciona a percepção de um instrumento construído e discutido de maneira lógica, em que não se garante a perpetuidade de um gasto.

As mudanças do orçamento são decididas pelo grupo gestor, que monitora as ocorrências. As várias entrevistas foram consistentes. As metas são desdobradas em vendas, com metodologia própria de projeção e plano industrial, que tem metodologia segmentada em longo, longuíssimo e curto prazo. Foi explicitado que existem indicadores corporativos e indicadores de áreas, e os elementos alcançam os profissionais. 
O grupo gestor aprova as metas que são propostas; levam em conta que tem que ser específica, ser relevante, temporal e exequível (existe desafio, mas podem ser atingidas). O nível de diretoria não admitiu a existência de reservas orçamentárias nas projeções e o controller entende que existem.

\subsubsection{Entrevistas com foco nas reservas}

Foram desenvolvidas a partir de diretores e gerentes que respondam para diretores e outros executivos envolvidos no processo orçamentário da empresa. A condução da pesquisa de campo leva em conta os elementos levantados anteriormente e os detalhes podem ser vistos na Figura 5.

\begin{tabular}{|ll|}
\hline \multicolumn{1}{|c|}{ Elementos } & \multicolumn{1}{c|}{ Descrição dos questionamentos } \\
\hline Existência da Reserva & $\begin{array}{l}\text { Como traduzir o que significa para os gestores subestimar receitas e superestimar } \\
\text { gastos? Entender o discurso dos gestores implica entender os possíveis parâmetros } \\
\text { considerados. }\end{array}$ \\
\hline Intencionalidade da ação & Como o superior avalia a existência da intencionalidade? Qual o seu raciocínio? \\
\hline Razões para a reserva ser criada & $\begin{array}{l}\text { Quais as principais razões para a criação de reservas no orçamento? As razões } \\
\text { citadas na literatura foram mencionadas pelos respondentes? }\end{array}$ \\
\hline Benefício da ação & $\begin{array}{l}\text { Pode existir ou pode não existir, ou quais benefícios podem ser obtidos a partir da } \\
\text { existência de reservas? }\end{array}$ \\
\hline
\end{tabular}

Figura 5. Condução das entrevistas com foco nas reservas

Fonte: Desenvolvido com base na literatura investigada

\subsection{Estruturação das entrevistas}

Algumas perguntas devem ser respondidas no que se refere à preparação e execução das entrevistas. Os pontos principais de preparação para as entrevistas foram os seguintes:

- Conhecimentos sobre as operações da empresa, no que se refere a localização, história, atividades principais, mensagens da empresa para o ambiente externo.

- Definição dos respondentes e negociação com a empresa. A porta de entrada da equipe de pesquisadores foi por meio da presidência da empresa a partir de um contato em uma palestra universitária. A presidente entendeu e cooperou com os pesquisadores no sentido de permitir o acesso e direcionar a equipe à controladoria da empresa, que direcionou o desenvolvimento da pesquisa.

- Protocolo ético de pesquisa. Foi apresentado ao executivo que proporcionou abertura para a realização dos trabalhos. Foi assinado pelos pesquisadores e pelo representante da empresa autorizando o desenvolvimento do trabalho, as regras de acesso, o compromisso de confidencialidade do nome da empresa e dos entrevistados, bem como o compromisso de apresentar uma devolutiva do estudo realizado.

- Preparação quanto aos jargões utilizados. Preocupou-se com a terminologia utilizada em termos de áreas, artefatos de gestão, ganhos, gastos, custos, lucro, despesas, etc.

- Maneira de conduzir as entrevistas específicas sobre reservas. As perguntas foram orientações para o diálogo sobre o racional dos gestores em termos de entendimento, atuação e sentido para as pessoas. Foram feitas perguntas gerais destinadas a buscar o entendimento dos gestores e, dependendo das suas respostas, aprofundadas, com a pretensão de ampliar o entendimento dos discursos. 
Destaca-se que as entrevistas foram gravadas com consentimento dos executivos da empresa e identificadas sequencialmente (por exemplo, g1D1, gravação 1 com o diretor 1).

\section{Análise e Discussão dos Resultados}

A análise levou em conta a estrutura especificada no construto apresentado, identificando: (i) o discurso que permeia a organização, (ii) os exemplos desses discursos no que se refere à retórica, em suas dimensões técnica, emotiva e representacional; e (iii) a literatura que dá sustentação à análise. A Figura 6 identifica o relacionamento entre os agentes (conselho de administração, diretoria e gerentes), os instrumentos utilizados e os discursos capturados na organização, de acordo com o construto proposto.

Conselho de administração Diretoria Gerentes

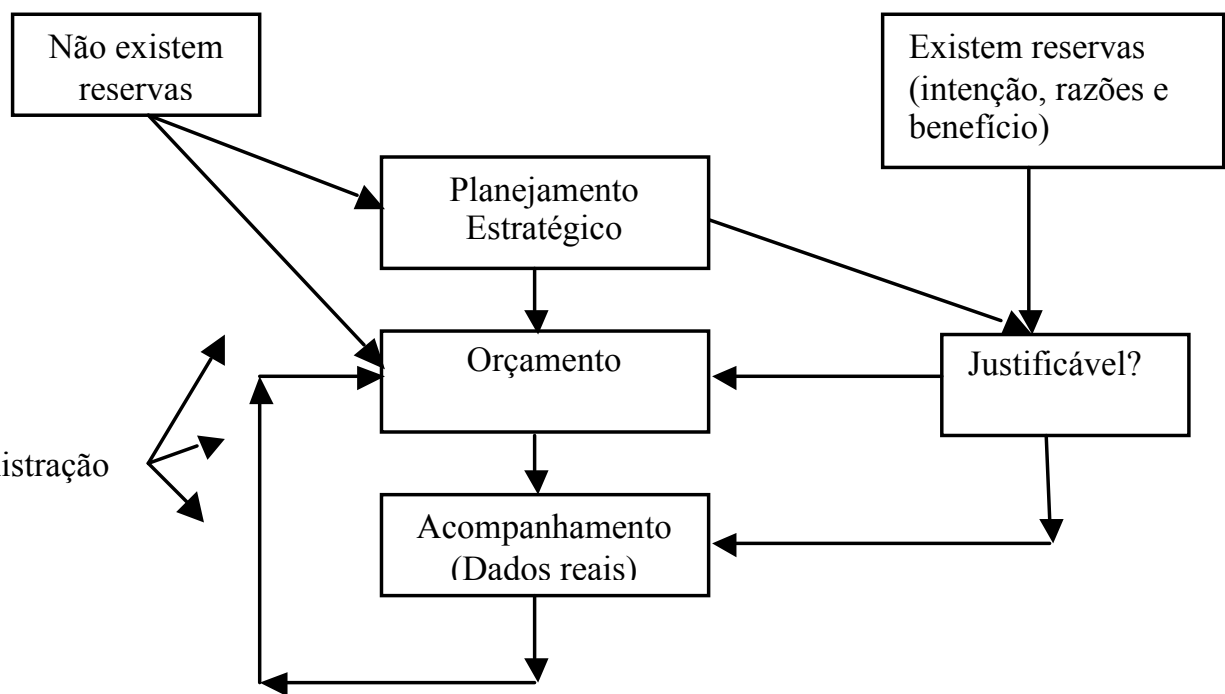

Figura 6. Sumário dos Elementos Tratados

Fonte: Dados da pesquisa.

A Figura 6 tem por objetivo identificar a relação entre os elementos captados pelos discursos. Nesse sentido, a análise foi estruturada de maneira a captar a realidade percebida a partir das diferentes visões, nos quatro elementos do construto. Dessa forma, os resultados são explorados em detalhes.

\subsection{A existência da reserva}

Os discursos dos executivos entrevistados foram assertivos e relativamente alinhados, com poucas metáforas e metonímias, sendo percebidas duas abordagens que convivem nos vários níveis: (i) não existência de reservas simplesmente, identificando projeções de metas "realísticas" ou (ii) a sua existência justificada como garantia para atingir metas maiores da organização:

Sujeito 1: “... tentamos fazer o orçamento com visão realista, nem pessimista, nem otimista."

Sujeito 2: "Não é prática dos gestores colocar alguma gordura nos gastos"

Sujeito 3: "A prática é tolerável em algumas circunstâncias e é recomendável para não correr riscos. Pode ter um custo adicional para trabalhar sábado ou domingo para atingir uma meta. É uma margem de segurança para aproveitar a venda dos Dias dos Pais, por exemplo, que é uma meta maior." 
Os respondentes que apresentam o discurso de que não reconhecem a existência da reserva têm essa crença fortemente ligada à visão de que a percepção de reserva seja algo objetivo que os executivos possam perceber se uma meta é realística ou não. Isso ocorre comparando-a com uma combinação de dados passados e decisões futuras. Outra visão considera a percepção, ou não, da constituição de reserva simplesmente "arte", analisando-a muito mais em decorrência da questão situacional do risco percebido, dependendo da área que lide com o orçamento. Trata-se de uma metáfora que indica quão difícil é alguém deliberadamente constituí-la:

Sujeito 3: "Intenção de fazer a reserva, é uma questão de arte, dependendo do nível do funcionário, inadmissivel".

Sujeito 4: "as metas tem que ser desafiadoras como sentido natural da vida... levando em conta que sejam exequíveis".

A existência de mecanismos legitima os números do orçamento. Nesse ponto, a argumentação - a justificativa - torna-se fundamental para a percepção da existência de reserva e sua aceitação ou não. Não houve muito interesse em discutir se as metas seriam desafiadoras ou não, pois a combinação entre o que foi atingido no passado e as estratégias resolveriam essa questão. Se o orçamento foi aprovado é porque é adequado e alinhado com as estratégias.

A percepção da não existência de reservas decorre da crença da objetividade do modelo de gestão da organização baseado: (i) no fato de que as metas orçamentárias são provenientes das estratégias definidas anteriormente pelo grupo gestor, o que proporciona legitimidade para gastos, já que foram aprovados; (ii) na amplitude de discussão do orçamento que envolve o conselho de administração, a diretoria e a gerência, ou seja, é muito desgastante ser pego em uma reserva não explicável; (iii) muito forte a prática de usar dados passados naquilo em que o futuro não é diferente; (iv) na análise para avaliar se existe adequação em termos de indicadores, ou seja, se o molde financeiro não se mostrar adequado, o valor não é aprovado. Toda a construção do discurso é racional no sentido de que existem mecanismos para que não existam reservas. As evidências são as seguintes:

Sujeito 1: "Avalia com base no histórico, no custo, no planejamento estratégico... a partir das metas globais saem as metas, que foram definidas anteriormente, e não da visão operacional."

Sujeito 1: "A transformação das metas estratégicas em metas orçamentárias vem da gerência. Passam pela diretoria e pelo conselho de administração."

Sujeito 2: "... a gente é muito sério na elaboração do orçamento. Somos questionados pelo diretor da área, presidente e conselho. Tudo tem que ser justificado. Se o diretor entender que tem algum gasto a mais ele manda cortar."

Sujeito 2: "Fazer reserva, só se for malandragem, pois, se o orçamento for bem feito, não precisará de reservas."

Sujeito 1: "Analisamos quantos por cento está sendo o custo direto em relação à receita líquida, por exemplo, e até o conselho de administração, diretoria e gerência acompanham."

Sujeito 3: "Uso como referencial o histórico, o mercado e a inovação."

Sujeito 3: "Para identificar usa a avaliação do orçamento, item a item, por falta de conhecimento, orientação, de entendimento a pessoa faz orçamento que não é adequado. Pede mais ar condicionado e não sabe que existe em outro lugar um ar condicionado disponível. Ou então alocação de viagens que podem ser substituídas por teleconferência ou outra forma. Analisando item a item isso pode identificar oportunidades."

Sujeito 4: "existem parâmetros para se saber se existem reservas: histórico, padrões de excelência. A discussão de processos: se você quer cortar custos, você precisa analisar processos."

Sujeito 6: “...dá uma olhadinha para trás mas vê o que é necessário para a frente. A metodologia éo orçamento base zero... busca ser o mais realista possível... a subestimação e superestimação vão causar algum problema na cadeia produtiva... temos revisões periódicas." 
Sujeito 7: “... a gente apresenta o orçamento e existe uma negociação. Por que eu botei esse valor? É muito difícil não ser aceito se argumentado. Depois o documento é assinado pelo gerente e diretor."

Sujeito 7: "Como foi o cenário do ano passado; se ele vai se repetir, eu sigo a tendência; se existem diferenças, faço adaptações."

Sujeito 7: "Nós temos quatro ou cinco metas que servem para todos os gerentes e se não são cumpridas somos cobrados. Se não atingiu o real neste ano, não vai deixar no ano que vem."

A crença no conjunto de mecanismos do modelo de gestão proporciona a sensação de que a reserva não existe. Provavelmente a utilização do orçamento base zero com seu processo de discussão colabore para isso. É como se o número "certo" fosse algo plenamente identificado levando em conta que existe uma referência que é o passado, a transparência proporciona uma percepção de legitimação dos números aprovados, ou então atuar para corrigir o orçamento quando existem problemas com as metas e, com isso, o "direito" de gastar o que foi pedido. A crença de que seja possível planejar e fazer ocorrer as ações é parte do discurso:

Sujeito 1: “...se só preciso de 10 funcionários, não posso ter 12 terei 10 e isso é monitorado o tempo todo." Sujeito 2: "...isso evoluiu muito. Existe uma troca de informações muito grande e o comercial sabe o que ocorre conosco e vice-versa. Sabemos a dificuldade um do outro em todas as áreas. Buscamos um orçamento que seja enxuto e justo para empresa e gestor da unidade."

Sujeito 4: "...tem que ter uma metodologia. Se o potencial de mercado é de 200 peças, devo projetar 200 e não 400."

Sujeito 5: "Acredito que a falta de um planejamento claro, de incertezas de mercado e a inflexibilidade para aceitação de erros, são potenciais motivos que podem levar a geração de reservas nas metas orçamentárias."

Sujeito 6: "Supervalorizar o orçamento só por um erro. Não gosto... Só pode aplicar quando não tiver base de informação. Por qualquer outro motivo não vejo como aplicar."

Sujeito 6: "... na discussão nós apresentamos provas de que precisamos gastar".

Sujeito 7: "O cara que sabe fazer o orçamento nem vai subestimar nem vai gerar um orçamento 'gorduroso'. Dizer que vai gastar cinco milhões e gastar três não faz sentido... se está orçado pode ser gasto; se não está orçado, tem que pedir."

Embora Merchant e Van der Stede (2007) afirmem que é improvável que não existam, com relação à literatura, a referência para se saber se existe reserva, um caminho é a análise das informações providas pelo sistema de informações que proporciona visibilidade e transparência, nos vários níveis hierárquicos (Young, 1985; Lukka, 1988; Dunk \& Nouri, 1998; Hobson et al., 2011). Esse fator reduz, quando não elimina, a assimetria de informações entre os níveis hierárquicos (Merchant \& Van der Stede, 2007). Essa combinação faz com que aquilo que é aceito seja entendido como não impregnado de reservas; se elas existirem são justificadas por serem necessárias. Dessa maneira, uma vez conhecidas as estratégias, os gestores estabelecem suas metas, definem recursos e os justificam. Esse processo de legitimação top-down faz com que o discurso da eficiência se "materialize" para um perfil de gestores no sentido de não existirem reservas, já que eles se sentem convencidos de que os recursos são necessários naquele nível ou as receitas são possíveis naquele patamar.

Nesse sentido, a ilusão do controle, tratado por Rosanas e Velilla (2005), se faz presente, pois, ao dispor de informações sobre o passado e as estratégias definidas para o futuro, os gestores se sentem seguros, mesmo que a ponte entre o passado e o futuro seja um conjunto de números e argumentos.

\subsection{Intencionalidade da ação}

Dado que a crença de que ao pressupor intenção da constituição de reservas orçamentárias, a percepção é de que a reserva é necessária e útil para a organização se mostra também legitimada, justificado 
como maneira de reduzir o risco do negócio. É entendido como maneira de apoiar um objetivo maior. No entendimento de Merchant e Van der Stede (2007), os benefícios desse tipo de reserva são a redução da tensão interna frente à mudança nas metas do orçamento, aumenta-se a chance de aceitação de mudanças dos gestores frente a momentos de mudança e proporciona condições de terem recursos em situações inesperadas.

Não existem reservas por causa dos mecanismos do modelo de gestão. Se elas existirem, serão intencionais e não escondidas, mas, sim, compartilhadas. Se surgirem fora dessas condições, existem mecanismos para detectá-las e excluí-las. As evidências são:

Sujeito 1: "Dificilmente um subordinado poderá gerar uma reserva sem ser intencional porque todo o orçamento é montado com base histórica do passado e com a projeção do futuro. Cada diretor avalia o orçamento de sua área. A margem histórica não permite margem."

Sujeito 4: "é natural que o ser humano se proteja. Em alguns casos por falta de informação e em outros para se proteger. Existem questionamentos para isso, levando em conta os processos. Para evitar isso, a controladoria passa o seu crivo, a diretoria pode trazer uma diretriz de corte de $10 \%$ por exemplo".

A questão da participação na discussão da reserva, eliminando a alternativa de que seja unilateral, é dosada, pois nem sempre pode ser compartilhada com todos os níveis, em decorrência de algum tipo de tensão:

Sujeito 1: "Algumas metas podem ser compartilhadas e outras não podem ser compartilhadas pelo efeito nos níveis hierárquicos mais baixos".

Captar a intenção de fazer reserva (Young, 1985; Lukka, 1988; Dunk \& Nouri, 1998) foi algo declarado em alguns casos, mas algo muito referente ao mundo da percepção e julgamento. $\mathrm{O}$ fato de não existir ligação entre metas atingidas e recompensas proporciona um olhar diferente: se não existe benefício financeiro direto para o executivo, por que fazer uma reserva? Foi mencionado que podem existir benefícios para a organização, o que torna mais fácil discutir o tema.

O presente caso mostra que existe a assimetria mencionada em relação à maior disponibilidade de informações por parte do funcionário em relação ao superior hierárquico (Merchant \& Van der Stede, 2007). Pode ser vista do outro lado, onde o superior hierárquico tem informações não compartilhadas com o subordinado. Isso pode provocar sentimento de desconfiança que justifique a criação da reserva orçamentária, no sentido de proteção a possíveis tensões, configurando, dessa forma, uma margem de segurança e/ou zona de conforto.

\subsection{Razões para as reservas serem criadas}

Foi admitido que podem ser feitas reservas no orçamento no caso de investimentos, quando, para não perder uma oportunidade de crescimento, colocam um valor de investimento em relação ao qual não existe muita certeza se realmente serão demandados. A literatura prevê esse tipo de ação no sentido de que os gestores estão alocando recursos para otimizar os resultados da empresa (Mohamed, 1973), não existindo benefício individual. Por outro lado, foi argumentado que o acompanhamento de desempenho possibilitaria ajustes para mais ou para menos em decorrência do desempenho e isso desestimularia reservas. De qualquer forma, no nível diretivo, essa reserva não é feita sem o conhecimento do grupo gestor, que a discute e gerencia:

Sujeito 1: "Se o grupo gestor, por algum motivo, planejar algum investimento que possa ser aceito no futuro, pode ser colocado no orçamento embora não se tenha segurança sobre o gasto". 
Nas situações em que a reserva é tolerada, é entendida como algo que pode acontecer por desconhecimento, maneira de enfrentar o risco, busca por conforto, facilitação para atingir metas:

Sujeito 3: "a constituição de reserva sempre é avaliada pela condição de conforto, sem risco e sem desafios sem trabalho maior, pesquisa mais detalhada, é fácil, simplesmente determinar valor e superestimar uma meta; é condição de entusiasmo, condição de realização de alto risco, motivação de continuidade de projeto em andamento, expectativa pessoal. Tem que saber separar isso e colocar através de dados reais que você tem, colocar as condições mais prováveis. Isso é identificado a todo momento." Sujeito 4: "... a superestimação de gastos mais relevante está ligada ao crescimento: a empresa está crescendo e eu preciso de mais estrutura."

Sujeito 6: "Quando vai aplicar em algo novo, outra marca, existe um referencial mas por segurança, pela incerteza, seja colocado um valor maior."

Sujeito 7: Se uma pessoa faz uma previsão e a variação é muito grande é porque não tem noção. Se a empresa deu condições de gastar é porque era adequada, que gestão está sendo feita se o gasto não ocorreu?".

Razões para criar a reserva estão ligadas aos estímulos que aparecem na vida das pessoas, entre as várias alternativas citadas na literatura, a principal razão seria a constituição de um hedge contra a incerteza (Mohamed, 1973; Merchant, 1985; Nouri, 1994; Leavins, Omer, \& Vilutis, 1995; Davis, Dezoort, \& Kopp, 2006). Foi evidenciada como razão relevante. Por outro lado, surgiram elementos (Lukka, 1988) citados na literatura, ligados a entusiasmo, expectativa pessoal, motivação de continuidade que são razões ligadas a aspectos de comportamento.

\subsection{Benefício da ação}

O receio de ter valores cortados foi o elemento apresentado como incentivo para constituição de reservas, embora conviva com a crença de que não ocorram:

Sujeito 1: "...às vezes a gente faz corte em decorrência do fluxo de caixa, embora sejam legítimos." Sujeito 3: Se houver metas superdimensionadas, desafiadoras é justo que sejam colocadas reservas orçamentárias para não colocar em risco o que foi planejado."

Sujeito 4: "cuidado com ao deixar de gastar hoje em propaganda, por exemplo, deixando de estruturar uma área. Você tem que avaliar a consequência para daqui a dois ou três anos".

Sujeito 5: "Afastar o desconforto de um estorno de receita ou complemento de despesa no futuro acredito serem os dois principais benefícios possíveis, mas como já comentei, esta subestimação das receitas e a superestimação das despesas precisa ser planejado com consciência e limites."

Sujeito 6: "Não vejo benefícios. Vejo que, de acordo com os valores, você pode se acomodar..."

Sujeito 7: "...talvez eu tivesse verba para algo que surgiu de última hora".

No discurso, os benefícios de uma reserva não se referem a remuneração como largamente explorado na literatura (Brownel \& Mcinnes, 1986; Dunk, 1993, Leavins et al., 1995; Yuen, 2004; Church et al., 2012). Isso pode ser dito porque a empresa não pratica remuneração variável individual atrelada ao orçamento. Em outras palavras, a abordagem tradicional, principalmente decorrente da Teoria da Agência, falha em apenas considerar que a reserva é constituída por decisão consciente e deliberada por desejar ser beneficiado pela avaliação da organização. Dessa maneira, não seria essa a motivação, mas poderiam ocorrer outras, tais como o benefício de não ter desgaste em novas negociações ou mesmo imagem pessoal do executivo que, ao ter um valor maior para gastar ou menor em termos de meta de faturamento a alcançar, terá menos pressão (Merchant $\&$ Van der Stede, 2007). Esses benefícios pessoais para o executivo que 
queira praticar a geração de reservas podem ser eliminados pelo modelo de análise do orçamento ao não ter um benefício individual, mas, sim, coletivo, ligado a "não colocar em risco o que foi planejado". Dessa maneira, o entendimento sobre a reserva se altera, sendo tolerada e até incentivada por algumas áreas.

\section{Conclusões}

As conclusões da pesquisa corroboram vários aspectos da literatura e trazem outros não evidenciados anteriormente. Com relação à existência de reservas, os discursos seguem duas direções: negação da reserva ou a justificativa para a sua existência. A negação decorre de uma lógica de legitimação da estrutura que valida as metas, de maneira tal que elas deixam de ser reservas, mas se tornam recursos necessários. Isso ocorre tanto a partir do discurso de que não existem reservas como do discurso de que elas são necessárias. Nesse sentido, o valor superestimado nos gastos (ou subestimado nas receitas) não é percebido como reserva, já que o argumento do risco vem em socorro do proponente.

O elo que permite aceitar que não existem reservas ou elas são necessárias, e mesmo benéficas para a organização, é a justificativa, a argumentação aceita, e que só é possível dada pelas condições estruturais, ou seja, uma forte discussão e definição na formatação top-down da estratégia, a existência de sistema de informações que diminua ou elimine a assimetria como elemento de fragilização do superior hierárquico em relação ao subordinado e ao envolvimento de vários níveis hierárquicos na validação das metas orçamentárias estabelecidas pelos gerentes na abordagem bottom-up.

Assim, a existência e aceitação da existência de reserva orçamentária, nesse caso parte da justificativa, discussão e argumentação do plano orçamentário, o que é um argumento diverso do que geralmente é encontrado nas pesquisas que abordam o tema "reservas orçamentárias" e que parte de sua própria definição, a qual já está carregada de um viés de extrema racionalização. Como as definições de Young (1985), Merchant (1985), Lukka (1988), Dunk e Nouri (1998), Merchant e Van der Stede (2007), Hobson, Mellon e Stevens (2011), Kilfoyle e Richardson (2011), nas quais existe um consenso de que um indicador importante para a reserva é a intenção e, em alguns casos, de maneira deliberada, de criar condições de benefício particular em detrimento dos benefícios da organização, ou seja, metas que não correspondem à estimativa realizada em um cenário normal, geradas com base nas informações disponíveis.

A perspectiva adotada neste trabalho permitiu ir além dessa conotação de expropriação de riqueza e, em vez de olhar apenas para a busca de proteção ou de benefícios particulares, buscou entender os motivos para a criação da reserva. O ambiente da organização propiciou identificar, ainda, mesmo sem estarem tão propensos a manipulação de informações orçadas para atingir resultados e receber incentivos pelo alcance desses resultados, pois no caso da empresa incentivos atrelados a metas orçamentárias, como remuneração variável não eram ofertados, a reserva, mesmo no caso da negação de sua existência, partia de uma conotação de proteção dos resultados organizacionais, que boa parte deve-se ao extremo ambiente de volatilidade.

Em suma, os discursos permitem entender os comportamentos que poderiam ser considerados extremamentes nocivos à organização, ao olhar racionalizador, e que, em decorrência do ambiente de crescimento e confiança, sugerem que a existência das reservas, no caso dessa organização, é algo que é gerenciado dentro da estrutura, principalmente em decorrência do ambiente econômico e da gestão ativa na empresa.

Nesse sentido, o conjunto de mecanismos iniciado pela definição de estratégias, o sistema de informações que possibilite disponibilidade de informações, o processo de discussão, a consciência de que a meta de uma área afeta a outra e a não amarração do desempenho das metas com a remuneração fazem com que a reserva orçamentária não seja um problema na organização. Como conclusão desse caso, pode-se dizer que a organização, independentemente dos discursos encontrados, pende claramente para a gestão da reserva dentro do seu ambiente organizacional. 


\section{Referências}

Alvesson, M. (2003). Beyond neopositivists, romantics, and a reflexive approach to localists: in organizational. Academy of Management Review, 28(1), 13-33.

Anthony, R. N. (1970). Management accounting. (4 ed.). Illinois: Irwin.

Anthony, R. N., \& Govindarajan, V. (2008). Sistemas de controle gerencial. São Paulo: McGraw-Hill Brasil.

Bourgeois III, L. J. (1981). On the measurement of organizational slack. Academy of Management Review, 26(1), 29-39.

Brownell, P., \& Mcinnes, M. (1986, October). Budgetary participation, motivation, and managerial performance. The Accounting Review, 61(4), 587-600.

Bruns, W. J., \& Waterhouse, J. H. (1975). Budgetary control and organization structure. Journal of Accounting Research, 13(2), 177-203.

Carrieri, A. P. et al (Org.). (2009). Análise do discurso em estudos organizacionais. Curitiba: Juruá.

Chen, C. C., \& Hsiung, H. H. (2010, March). Understanding dynamic capabilities by transformation of organizational slack. Northeast Decision Sciences Institute Proceedings, 105-110.

Chen, C. J., \& Huang, Y. F. (2010, April). Creative workforce density, organizational slack, and innovation performance. Journal of Business Research, 63(4), 411-417.

Cheng, J. L. C., \& Kesner, I. F. (1997). Organizational slack and response to environmental shifts: the impact of resource allocation patterns. Journal of Management. 23(1), 1-18.

Chenhall, R. H., \& Morris, D. (1986). The impact of structure, environment, perceived on the interdependence usefulness of management accounting systems. The Accounting Review, 61(1), 16-35.

Chow, C. W., Cooper, J. C., \& Waller, W. S. (1988). Participative budgeting: effects of a truth-inducingpay scheme and information asymmetry on slack and performance. The Accounting Review, 63(1), 111-122.

Church, B. K., Hannan, R. L., \& Kuang, X. (2012). Shared interest and honesty in budget reporting. Accounting, Organizations and Society, 37(3), 155-167.

Covaleski, M. A., Evans III, J. H., Luft, J. L., \& Shields, M. D. (2003). Three theoretical perspectives and criteria for selective integration. Journal of Management Accounting Research, 15(1), 3-49.

Davila, T., \& Wouters, M. (2005). Managing budget emphasis through the explicit design of conditional budgetary slack. Accounting, Organizations and Society, 30(7-8), 587-608.

Davis, S., Dezoort, F. T., \& Kopp, L. S. (2006). The effect of obedience pressure and perceived responsibility on management accountants' creation of budgetary slack. Behavioral Research in Accounting, 18(1), 19-35.

Dittrich, I. J. (2008). Por uma retórica do discurso: argumentação técnica, emotiva e representacional. Alfa, 53(1), 21-37.

Dunk A. S. (1993, April). The effect of budget emphasis and information asymmetry on the relation between budgetary participation and slack. The Accounting Review, 68(2), 400-410.

Dunk, A. S., \& Nouri, H. (1998). Antecedents of budgetary slack: a literature review and synthesis. Journal of Accounting Literature, 17, 72-96.

Fairclough, N. (1992). Discurso e mudança social. Brasília: Editora Universidade de Brasília.

Ferreira, A., \& Otley, D. (2009).The design and use of performance management systems: an extended framework for analysis. Management Accounting Research, 20(4), 263-282. 
Frezatti, F. (2007). Orçamento empresarial: planejamento e controle gerencial. São Paulo: Atlas.

Frezatti, F., Nascimento, A. R., Junqueira, E., \& Relvas, T. R. S. (2011). Processo orçamentário: uma aplicação da análise substantiva com utilização da grounded theory. Organizações \& Sociedade, 18(58), 445-466.

Frezatti, F., Relvas, T. R. S., Junqueira, E., Nascimento, A. R., \& Oyadomari, J. C. (2010). Críticas ao orçamento: problemas com o artefato ou a não utilização de uma abordagem abrangente de análise? Advances in Scientific and Applied Accounting, ASAA, 3(2), 190-216.

Frezatti, F., Rocha, W., Nascimento, A. R., \& Junqueira, E. (2009). Controle gerencial: uma abordagem da contabilidade gerencial no contexto econômico, comportamental e sociológico. São Paulo: Atlas.

Giddens, A. (1979). Central problems in social theory: action, structure and contradictions in social analysis. Berkeley: University of California Press.

Hansen, S. C., \& Van der Stede, W. A. (2004). Multiple facets of budgeting: an exploratory analysis. Management Accounting Research, 15, 415-439.

Hartmann, F. G. H., \& Maas, V. S. (2010, January). Why business unit controllers create budget slack: involvement in management, social pressure, and machiavellianism. Behavioral Research in Accounting, 22(2), 27-49.

Hewege, C. R. A. (2012, December). Critique of the mainstream management control theory and the way forward. SAGE Open, 2 (4), 1-11.

Hobson, J. L., Mellon, M. J., \& Stevens, D. E. (2011). Determinants of moral judgments regarding budgetary slack: an experimental examination of pay scheme and personal values. Behavioral Research In Accounting, 23(1), 87-107.

Jensen, M. C., \& Meckling, W. H. (1976). Theory of the firm: managerial behavior, agency costs and ownership structure theory of the firm: managerial behavior, agency costs and ownership structure. Journal of Financial Economics, 3(4), 305-360.

Kakkuriknuuttila, M., Lukka, K., \& Kuorikoski, J. (2008, February). Straddling between paradigms: a naturalistic philosophical case study on interpretive research in management accounting. Accounting, Organizations and Society, 33(2-3), 267-291.

Keating, P. J. (1995). A framework for classifying and evaluating the theoretical contributions of case research in management accounting. Journal of Management Research, 7(1), 66-79.

Kenis, I. (1979). Effects of Budgetary Goal: characteristics on managerial attitudes and performance. The Accounting Review, 54(4), 707-723.

Kilfoyle, E., \& Richardson, A. J. (2011). Agency and structure in budgeting: thesis, antithesis and synthesis. Critical Perspectives on Accounting, 22(2), 183-199.

Lambert, R. A. (2006). Agency theory and management accounting. Handbook of Management Accounting Research, 1(6), 247-268.

Leavins, J. R., Omer, K., \& Vilutis, A. (1995). A comparative study of alternative indicators of budgetary slack. Managerial Finance, 21(3), 52-67.

Lukka, K. (1988). Budgetary biasing in organizations: theoretical framework and empirical evidence. Accounting, Organizations and Society, 13(3), 281-301.

Malmi, T., \& Brown, D. (2008, December). Management control systems as a package. Opportunities, challenges and research directions. Management Accounting Research, 19(4), 287-300.

Marginson, D., \& Ogden, S. (2005, July). Coping with ambiguity through the budget: the positive effects of budgetary targets on managers' budgeting behaviors. Accounting, Organizations and Society, 30(5), 435-456. 
Merchant, K. A. (1985). Budgeting and the propensity to create budgetary slack. Accounting, Organizations and Society, 10(2), 201-210.

Merchant, K. A., \& Van der Stede, W. A. (2007). Management control systems: performance measurement, evaluation and incentives. Pearson.

Miles, R. E., \& Snow, C. C. (1978). Organizational strategy, structure and process. New York: McGraw-Hill.

Mohamed, O. (1973, July). Factor analysis of behavioral variables affecting budgetary slack. The Accounting Review, 48(3), 535-548.

Moizer, P. (2009, February). Publishing in accounting journals: a fair game? Accounting, Organizations and Society, 34(2), 285-304.

Nouri, H. (1994). Using organizational commitment and job involvement to predict budgetary slack: a research note. Accounting, Organizations and Society, 19(3), 289-295.

Rosanas, J. M., \& Velilla, M. (2005, March). The ethics of management control systems: developing technical and moral values. Journal of Business Ethics, 57(1), 83-96.

Tan, J., \& Peng, M. W. (2003, December). Organizational slack and firm performance during economic transitions: two studies from an emerging economy. Strategic Management Journal, 24(13), 1249-1263.

Thaten, M., Mahlendorf, M., \& Skiba, O. (2010, May 15) Environmental uncertainty, participative budgeting, and the mediating role of reasons-to-budget. (Submission draft, pp. 0-45).

Torfing, J. (1999). New theories of discourse: Laclau, Mouffe and Zizek. Oxford: Blackwell.

Welsch, G. A. (1986). Orçamento empresarial. (4 ed.). São Paulo: Atlas.

Yin, R. K. (1985). Estudo de caso: planejamento e métodos. (2 ed.). Porto Alegre: Artmed, 2005.

Young, M. (1985). Participative budgeting: the effects of risk aversion and asymmetric information on budgetary slack. Journal of Accounting Research. 23(2), 829-842.

Yuen. D. C. Y. (2004). Goal characteristics, communication and reward systems, and managerial propensity to create budgetary slack. Managerial Auditing Journal, 19(4), 517-532. 